\title{
Problems in Editing Mark Twain ${ }^{\dagger}$
}

\author{
W I L L I A M B. TO D D
}

On July ninth of last year various Innocents at Home progressed to Iowa City, headquarters of the forthcoming Mark Twain edition, there to consider the rapidly developing complications of the project entrusted to their care. On the way some editors, I believe, found solace in the thought that there was really nothing to do. Life magazine had just declared that all of Twain was written by Longfellow. ${ }^{1}$ The present writer worried over quite a different report, Henry M. and D. C. Partridge's The Most Remarkable Echo in the World, which not only authenticated all of Twain's writings but assigned to him the work of Edgar Allan Poe, Nathaniel Hawthorne, and Lewis Carroll. ${ }^{2}$ The year after this great disclosure, in 1934, one of these authors also attributed to Twain the entire corpus of Rudyard Kipling and the forgeries of Thomas J. Wise. ${ }^{3}$ Somewhere within these lunatic fringes, we may be assured, lies the real Twain: a vast international territory demanding, for its proper government, a ministry of all the talents, a search through countless newspapers and journals, an inspection of hundreds of reference works, the collation by machine and by eye of perhaps 400 texts-this an estimate for major works only-the compilation of thousands of variant readings and, at last, the production of some thirty-six volumes, the twelve from the University of California at Berkeley representing work not previously in print, twenty-three others from Iowa exhibiting in definitive form work already published, and a final volume providing for the whole a bibliography and index.

†This paper was read at the annual meeting of the Modern Language Association in New York 27 December 1964.

1 D. J. Hamblin, "Mark (ye) (the) Twain," Life, 10 July 1964, p. 13.

2 Henry M. and D. C. Partridge, The Most Remarkable Echo in the World, New York, 1933. Privately printed in 100 copies.

3 Henry M. Partridge, "Did Mark Twain Perpetrate Literary Hoaxes?" American Book Collector V (December 1934), pp. 351-57; VI (January 1935), pp. 20-23; (February 1935), pp. 50-53. 
Except in one important particular, to be considered last of all, the editorial board has accepted and intends to apply the principles recently expounded by Professor Bowers at Miami Beach and more recently demonstrated in the Hawthorne (if it is really Hawthorne) edition now issuing from the press. ${ }^{4}$

Of first importance is a means of bringing under control and then refining in a certain procedure the diverse materials to be examined. The entire output of Twain, as measured only by cards filed at the Union Catalogue, Library of Congress, consists of some 2,650 variant issues. Even if this total is reduced first to issues in Twain's lifetime, then to the variants of a single work-The Innocents Abroad, let us say-the count still runs to forty issues, twenty-six beyond the count in the Bibliography of American Literature. Viewed as arithmetic totals these figures are rather unmanageable, however talented the ministry, but regarded as multitudinous printings from relatively few electrotype plates, the usual condition, the situation is brought within easy compass and can be expressed in formulae applicable at least to Twain's major works. An analogical scheme is now also being devised for the minor writings. Thus for any book the sigla may consist of from one to three elements:

1. A capital letter designating the national origin of the setting and comprising all plates of that setting, including those used earlier or later at some distant time or place. For separate authorized settings four letters will be used, ACEG, representing plates originating in America, Canada, England, and Germany. In this arrangement such variants as the earlier Canadian issue of Adventures of Huckleberry Finn, or the later English issue of Christian Science, can be subsumed under $A$, the original American setting, and then machine-collated as a part of the $A$ sequence. As for $G$, the editions issued by Tauchnitz in Leipzig, the fact that Twain once here provided a new introduction, and then expressed some inclination to revise the text, obliges us to read all thirty-three volumes in this series.

2. If there is more than one setting of the same nationality, the letter will be followed by a numeral. This numeral, however, does not signify any textual relationship between the two editions. Text E2 of Innocents Abroad (Chatto and Windus, 1881) for some odd reason does not derive from the earlier and revised E1 (Routledge, 1872), but from the original unrevised A (Hartford, 1869). Again in The Adventures of Tom Sawyer, E2 derives directly from A, and now with

4 Fredson Bowers, "Some Principles for Scholarly Editions of Nineteenth-Century American Authors," Studies in Bibliography XVII (1964), pp. 223-28. 
good reason, for $A$ here represents some textual improvement over E1.

3. Within a given setting A, E1, or whatever, any variant state will be signified by a lower-case letter. This reference applies only to textual variation in any group of impressions, all comment on typographical peculiarities, including reset but invariant words, lines, paragraphs, being reserved for the bibliography. Thus for The Gilded Age, a highly complicated $A$ setting, the textual state may be simply represented as a, b, c, with $a$ for the 1873 'Eschol' state, $b$ for the 'Beriah' state, and $c$ for the state further revised in 1895. A later printing of 1901 comes also from the earliest plates and thus is classified as of the $a$ group.

Now with these three-element sigla we can defer, until after collation, the assignment of the final a, b, c orders, and classify beforehand all the books to be considered. Of printed texts the total authorized settings are, at the one extreme, Christian Science, only two, and at the other extreme, The Prince and the Pauper, no less than eight.

Beyond the early printed texts there also lie a seemingly unending series of collected editions, at last count extending to twenty-seven issues under sixteen names and published by at least five different firms. Again, however, a plate analysis reduces all this confusion to three settings, now to be assigned the terminal letters $\mathrm{X}, \mathrm{Y}, \mathrm{Z}$. The relevance of these texts to a definitive edition requires separate comment.

$X$. An abortive series of five volumes produced in the so-called Harper 'Uniform' edition and reviewed by W. D. Howells in the 13 February 1897 issue of Harper's Weekly. All of these are undated and bear no helpful code-reference. At the time of the Iowa meeting only one exemplar had been identified-a solitary copy among some 5,000 specimens at Texas-but that one, of The Prince and the Pauper, exhibited a distinctive house-style which has since enabled us to locate all the others. Doubtless setting $\mathrm{X}$ will contribute little toward a definition of the text; yet as an authorized edition it must be collated in the automatic, unvarying process devised for all works.

$Y$. A sequence extending from twenty-two to thirty-seven volumes, issued initially by the American Publishing Company in 1899, then by several other firms, and finally by Harper in a series of coded issues the last reading D-R, or April 1917. Thus the impressions range over nineteen years, twelve before and seven years after the death of the author. Of all the complications in $Y$ the pitiful sum of our knowledge, at the time of the Iowa conference, was that different issues of the first volume immediately exhibited a score of variants, the first appearing in the very first sentence. Since then the Hinman Collator has been 
scanning first and last issues and, though only one-third the way through the job, promises to extract a phenomenal number of readings far exceeding the total exposed in any other editorial enterprise. Thus far the count is 92 for A Connecticut Yankee in King Arthur's Court, 152 for The Prince and the Pauper, 212 for Joan of Arc, 315 for A Tramp Abroad, 338 for Roughing It, and 367 for The Gilded Age. At this rate the corrected plates in the twenty-two volumes should produce some 4,500 variants, all these within the last setting in Twain's lifetime and-since the edition is plated-all therefore representing deliberate alterations unsullied (or unsallied if you prefer) by the corrupting effects of new composition. This situation, unparalleled, I believe, in editorial history, for awhile sent the editors, already exhausted by earlier labors, reeling into a state of shock. Most of them recovered somewhat when it was determined that 80 per cent of the variants restored the first edition text, one grossly abused by those who prepared the 1899 plates. But what authority, if any, resided in the other 20 per cent now first appearing?

No sooner was the question raised than Professor Salomon found an answer in a marked set at Yale. This issue of 1899, called the "Royal Edition,' obviously served if not directly as copy for the corrected impressions, then certainly as the text where all problems were decided. To simplify considerably, green crayon marks in this signify restorations, all billed against the firm of Case, Lockwood, and Brainard, printer of the original 'Autograph' impression, and red crayon marks designate new readings, all charged to the publisher. The copy also reports, for many readings, a lively debate between one 'FM,' a learned and opinionated corrector, and 'FEB,' or Frank E. Bliss, the proprietor of the American Publishing Company, here often forced to consult with the final authority, Twain. Thus in a short story, where reference is made to 'the creator of Frankenstein,' FM retorts 'This is terrible, for it shows Twain has never read Frankenstein. Frankenstein was the name of the creator, not the man monster, who is nameless.' FEB then remarks, 'Twain indicates that the phrase "the creator of" is to be struck out.' At other times FM expresses his dismay in such terms as 'absurd,' Tudicrous,' 'This is awful,' or 'This is an awfully stupid blunder.' All this leads FEB to telephone Twain, to consult Webster's Dictionary, to peruse the Book of Mormon, to admit some doubt 'I reckon so,' or simply to concede defeat 'Dunno.' As the dialogue proceeds we stand as delighted witnesses, here observing much of what we would otherwise have to do in 1965, now being done, indirectly with Twain's approval, in 1899. Coincidentally Y (or rather 
$\mathrm{Yb}$, second state) is an appropriate symbol for this edition, for it constantly reminds us of the Yale text, the final arbiter on many doubtful matters.

Z. A setting first plated as the code would indicate in July 1917 (three months after the last impression of $\mathrm{Y}$ ) and still available, from other plates, in this year 1965. The collation of this setting proceeds in observance of the principle that inspection should extend to one edition beyond the last in the author's lifetime. Moreover, even if there were no such principle, the editors of Twain would be forced to consider, in this setting, two impressions, the 'Definitive Edition' of 19221925 and the 'Stormfield Edition' of 1929, this last an issue fondly regarded by some Twainians as even more definitive than the 'Definitive.' Actually, of course, both are the same, and both textually inferior to anything that has gone before.

Apart from all other sigla, ACEG for separate editions, XYZ for collected, there appears among collational symbols one other letter, I. This could be understood as I the editor, I the intermediary, or I Claudius, the final judge of Twain's destiny. Formally it denotes no personal act, but the necessary intrusion of the editor, with the concurrence of the Iowa board, to correct manifest error or ambiguity. Despite the tendency of FEB, in the $\mathrm{Y}$ setting, to normalize the abnormal, and particularly to alter on his own authority a number of accidentals-some fifty-three, for example, in The Gilded Age-the editor will reject all such attempts and, so long as the earlier reading is defensible, even on the most tenuous grounds, preserve the reading against every assault. All optional spellings, idiosyncratic pointing, and misquotation, purposeful or not, must remain and then, if necessary, be explained in the notes. Even a misspelling, 'straightened' for 'straitened' in The Gilded Age, should be tolerated, I believe, if it represents a common fault or possibly, as here, a pun. But the misspelling of a proper name if unintentional, Russell for Russel, Septimius for Septimus, should be amended, for in these instances, surely, Twain would wish to be right or, at least, would have nothing to gain by being wrong. Pointing which is inconsistently employed, e.g. end quotes before period, or which distorts the meaning, must also be set aright, as Twain again would approve. Beyond these trivialities, however, these evident mistakes, these mechanical errors, the editor will not go.

With Twain the editor also dares not proceed very far in the other direction, that is, in substituting for first edition readings those of anterior texts in manuscript, typescript, proof, or other printer's copy. 
Unlike Hawthorne's carefully fashioned manuscripts, Twain's essentially are drafts, more often than not hurriedly written with ampersands, dashes, abbreviations, and other kinds of shorthand, then in this form amended, cancelled, extended, and then again as all evidence indicates gradually refined to the form perfected in print. For Twain the printed form was the ultimate state, a condition in which, given his own expertise as printer and publisher, he was fully competent to perform-when he chose to do so. Thus, contrary to practice in the Hawthorne edition, the editors of Twain have good reason to rely primarily on the earliest printing.

Even so, the editors will scrutinize every word before that printing, convey in notes every reading thereafter amended, and again, if necessity requires, intrude upon the text certain trivialities overlooked in the larger effort. When Jean Clemens, in typing her father's manuscript of Christian Science, silently elides a word or two, the loss, though not affecting the sense, must still be made good. And when C. D. Warner, while attending the American edition of The Gilded Age, alters a Twainian reading Twain himself retains in the English issue, again the intent here thwarted must prevail. But when Twain declares that his wife was 'perfectly right' in suppressing a chapter of Following the Equator, or allows W. D. Howells to revise the proofs of The Prince and the Pauper, then we may not claim an authority which Twain has expressly delegated to others. The confidence in others may be misplaced, the passage deleted of greater interest than anything retained; but whatever the significance of the reading we may not restore it-even in brown ink, according to the latest fashionand thus violate Twain's will in the matter. Throughout the edition, then, through the entire mass of variants before and after original printing, our constant endeavor will be to represent Twain, not as our present inclination might suggest, but as he in his own time would have us do it, with warts and all. 